\title{
A FOTOGRAFIA E O SEGREDO
}

\author{
Emiliano Dantas ${ }^{1}$ \\ Renato Athias ${ }^{2}$
}

\section{Introdução}

No ano de 2006, foi iniciada uma pesquisa chamada de Imaginário dos Orixás em Pernambuco ${ }^{3}$, que tinha o intuito de estudar/mapear o Candomblé em Pernambuco. Para isso, foi formada uma equipe composta por antropólogos, estudantes de pósgraduação em Antropologia, um fotógrafo e um consultor na Bahia ${ }^{4}$. Essa consultoria foi o motivo que levou a pesquisa até os terreiros em Ilhéus e Itabuna - ambas cidades baianas - como base comparativa para os trabalhos no Recife.

O consultor da pesquisa comanda o terreiro Ilê Axé Ijexá Orixá Olufon, em Itabuna. Nesse terreiro é proibido fotografar no barracão ${ }^{5}$, tanto quando estivesse vazio, quanto durante as comemorações para os Orixás. A documentação fotográfica já tinha sido feita em outros terreiros no Recife para o Projeto, motivo esse que provocou um estranhamento em relação aquela proibição, porque até então, nas demais casas ${ }^{6}$ pesquisadas, o que era proibido fotografar estava relacionado ao sacrifício de animais. Até aquele momento o grupo de pesquisadores não tinha se deparado com tamanho rigor e, por isso, esta restrição serve como o ponto de partida para o desenvolvimento dessas reflexões.

A partir dos limites impostos pelos integrantes dos terreiros, pretende-se refletir sobre a relação entre o Termo de Consentimento Livre e Esclarecido de participação na pesquisa e a autorização de uso de imagem ${ }^{7}$. Assim, segue-se no sentido de tencionar uma busca por uma ética de pesquisa que resguarde os direitos dos participantes e do fotógrafo, desde o início da pesquisa até aqueles momentos que fazem parte do

\footnotetext{
${ }^{1}$ Universidade Federal de Pernambuco, Brasil.

${ }^{2}$ Universidade Federal de Pernambuco, Brasil.

${ }^{3}$ A pesquisa foi realizada vinculada ao Núcleo do Imaginário do Programa de Pós-Graduação em Antropologia da Universidade Federal de Pernambuco, sob a orientação da professora doutora Danielle Perin Rocha Pitta.

${ }_{5}^{4}$ O consultor foi Ruy Povoas, babalorixá e professor da Universidade Estadual de Santa Cruz - UESC.

${ }^{5}$ Local onde as festas e toques para os Orixás ocorrem.

6 "Casa" é uma das formas como os integrantes do candomblé de Pernambuco se refere aos terreiros.

7 “Caso seja necessário utilizar imagens obtidas com os participantes do projeto, deverá ser solicitada uma Autorização para Uso de Imagem, que pode ser incluída como um item dentro do Termo de Consentimento Livre e Esclarecido. Nesta autorização, deverá constar a forma e a utilização previstas para as imagens." (Franciscone; Gondim, 2000) http://www.uftm.edu.br/upload/ensino/Termo\%20de\%20Consentimento.pdf, acesso em 03/07/2012.
} 
inesperado, o imprevisível, chamado por Malinowski (1978) "os imponderáveis da vida real", que em geral ocorre em pesquisas extensas, como foi o caso dessa experiência vivenciada no Projeto Orixás de Pernambuco, que servirá como base empírica para esse texto.

Seguindo os acontecimentos da pesquisa, propõe-se transpor os limites da pesquisa feita com o Núcleo do Imaginário, que terminou em 2007, para chegar até 2012, no terreiro Ilé Iyeminjá Ògunté, onde foram presenciados alguns acontecimentos, que influenciaram nessa relação de proibição e permissão para fotografias em casas de candomblé.

\section{O consentimento livre e esclarecido}

O código deontológico da antropologia ${ }^{8}$ dita os direitos do antropólogo e do grupo social estudado que é objeto da pesquisa. Nele está contido uma série de informações que visam garantir um contrato ético entre as partes envolvidas, de forma clara, com uma linguagem inteligível, para pessoas com baixa escolaridade ou analfabetas. O objetivo do termo é o consentimento livre de participação esclarecida em uma pesquisa, de preferência assinado. Nesse sentido, Achutti (2004) comenta a respeito de sua preocupação em estabelecer relações éticas:

É durante o trabalho de campo que se estabelecem as trocas e as relações intersubjetivas, e é nesse processo de conhecimento que se dão as condições para interpretações que vão conduzir ao relato etnográfico. Portanto, no âmago desse processo e de reencontros intersubjetivos, é preciso questionar-se sempre a respeito da deontologia; mais do que nunca, é nesse momento que se precisa saber respeitar os direitos, os valores e, por que não, até mesmo os sonhos dos "outros".

(Achutti, 2004: 118)

Como estamos tratando de técnica de pesquisa que se apropria de imagens, vamos acrescentar nesse termo a autorização de uso de imagem. Esta deve deixar claro a intenção e as mídias que as imagens do "outro" vão ser vinculadas. Todos esses cuidados vão diminuir a possibilidade de uso indevido de imagem e possíveis reprovações do projeto quando submetidos a comissões de ética que avaliam as diretrizes e normas reguladoras que envolvem pesquisas com seres humanos ${ }^{10}$.

\footnotetext{
${ }^{8}$ Disponível em: http://www.abant.org.br/?code=3.1

${ }^{9} \mathrm{O}$ significado da palavra Outro neste texto procura se desvencilhar de características hierarquizantes e etnocêntricas, ver Achutti (2004).

${ }^{10}$ (Franciscone e Gondim) http://www.uftm.edu.br/upload/ensino/Termo\%20de\%20Consentimento.pdf, acesso em 03/07/2012.
} 
Ademais, o cuidado com as pessoas que são objetos de pesquisas deve levar em consideração que elas geralmente não pedem para ser estudadas, na maioria das vezes, o antropólogo é quem propõe a interação e participação do "outro" na sua pesquisa (Achutti, 2004).

Em 2006, teve uma reunião com os integrantes do Núcleo do Imaginário com a finalidade de discutir qual seria o Termo de Consentimento Livre e Esclarecido a ser utilizado pelos pesquisadores nos terreiros. Ao final da reunião, foi feito um termo que esclarecia os objetivos da pesquisa, mas naquela época ainda não era comum a aplicação do termo de autorização de uso de imagem com frequência. Então, todos estes aspectos ficaram incluídos em um mesmo documento que só tinha descrito o pretenso produto da pesquisa: um livro. Sendo assim, todo aquele material estava sendo liberado para uma única veiculação. Não foram mencionadas as possibilidades de artigos, outras mídias correspondentes ao projeto, ou mesmo outros produtos derivados daquela pesquisa. Nada foi acordado além do livro. Essa foi uma limitação que culminou na inutilização de mais de 7.000 fotos e horas de entrevistas gravadas, uma vez que o livro nunca foi publicado.

Explicar para um grupo a sua intenção muitas vezes é uma tarefa difícil, que requer tempo e compreensão. Durante um dia, o pesquisador/fotógrafo pode ter que repetir e esclarecer as intenções da pesquisa para várias pessoas diferentes e isso requer saber falar o idioma do "nativo", para que, além de ser autorizado, possa se fazer a etnografia, que consiste em "descrever um grupo humano - suas instituições seus comportamentos interpessoais, suas produções materiais e suas crenças” (Agrosino, 2009). Nesta direção, Franz Boas salienta que "etnólogo, por outro lado, comprometese, na maioria dos casos a elucidar os mais íntimos pensamentos e sentimentos de um povo...” (Boas, 1911: 59). Fica difícil ter informações de qualidade sem falar a língua do "outro", essa é uma tarefa crucial no trabalho de campo.

Logo no início da pesquisa realizada com o candomblé, sentiu-se necessidade de aprender quais eram os termos ${ }^{11}$ que faziam parte da comunicação dos terreiros. Então, há uma pessoa que se faz muito importante para aproximação de um grupo de pesquisadores: um "informante". Nesse caso, compartilha-se da opinião de Márcio Goldman (2006), que não gosta do termo "informante", pois é um termo infame usado

\footnotetext{
${ }^{11}$ Os termos são geralmente falados em Iorubá em Recife.
} 
pela polícia para caracterizar um "dedo-duro" ${ }^{12 \%}$

A pessoa que introduziu o grupo de pesquisadores nos terreiros urbanos de região metropolitana de Recife foi o Babalorixá José Cláudio das Neves. Consequentemente, ele se tornou amigo do grupo. A ligação com Claudio levou alguns integrantes a frequentar o bairro de Rio Doce, onde ele mora, participando de feijoadas e festas em sua casa e, algumas vezes, dando uma ajuda, em alguns serviços religiosos que ele executava. Assim, foi construída uma amizade e um conhecimento que começava a instrumentalizar o olhar do grupo (Dantas, 2011) para fotografar e pesquisar o candomblé em Pernambuco. A aproximação ajudou a qualificar o olhar dos pesquisadores para trabalhar com a representação do "outro", que pensaremos como no texto "Balinese Character (Re)visitado" por Etienne Samain, que diz: "De tal modo que toda tentativa de compreensão dos fatos de cultura nunca será outra coisa se não a representação da representação, isto é, no melhor dos casos, o esforço de uma contextualização, de uma nova enunciação e de uma nova interpretação..."(Etienne Samain, 2004: 67).

Claudio é um "amigo" dos tantos adquiridos ao longo de anos de pesquisas em lugares inóspitos, de extrema pobreza e de violência. Estabelecer e firmar uma amizade que possa fazer uma inserção no campo é uma ajuda importante, principalmente sempre que o pesquisador é um estrangeiro com as incertezas e duvidas do desconhecido. $\mathrm{O}$ "amigo" é imprescindível para o aprendizado da língua, dos possíveis limites de onde podemos ir e quais as implicações de investidas em locais perigosos, e um fator fundamental é que ele dará uma credibilidade para a inserção do pesquisador no grupo a ser estudado.

A entrada no campo é uma primeira etapa que requer um cuidado e um estudo para que não ocorram rejeições com a presença do pesquisador. No segundo momento após o contato, ocorre a apresentação das intenções de pesquisa para conseguir a autorização do grupo. Para os trabalhos que envolvem áudio e imagem temos a câmera, que quando incluída na metodologia, costuma deixar mais difícil a relação, já que as pessoas costumam alterar os seus comportamento ao se verem diante dela. Ou seja, defronte a câmera, as pessoas costumam produzir uma postura que acreditam ser aquela que corresponde a um respeito social - o "outro" vai arrumar sua aparência pensando em como as pessoas do seu grupo social esperam que ela apareça produzindo uma

\footnotetext{
${ }^{12}$ Termo muito usado em Recife para representar um sujeito que entrega os seus amigos de atividades ilegais.
} 
postura que imponha respeito (Bourdieu, 1959).

Não devemos desprezar essa forma de representação ${ }^{13}$, que ocorre geralmente nos primeiros contatos com o grupo estudado, mas para que essa compreensão aconteça de uma forma mais aprofundada e menos superficial, podemos seguir a sugestão de André Alves que escreveu uma obra importante na antropologia visual do Brasil, intitulada "Os argonautas do Mangue”. Nesse livro, ele discursa da seguinte forma sobre a interação de pesquisa entre os envolvidos:

[...] a minha inserção e aceitação por parte dos caranguejeiros dessa comunidade foi o fato de ter participado efetivamente do seu cotidiano de trabalho, seguindo o conselho de Bronislaw Malinowsky: “[...] recomenda-se ao etnógrafo que de vez em quando deixe a máquina fotográfica, lápis e caderno, e participe pessoalmente do que está acontecendo",14.

(Alves, 2004: 110)

O envolvimento e a participação do pesquisador com o grupo ajuda no sentido de ganhar a confiança das pessoas que estão participando da pesquisa. Esse movimento de envolvimento firma uma relação de confiança, ajuda ao pesquisador a distinguir as atitudes das pessoas, como colocou Geertz (1998; 5), distinguir entre piscadela e tique nervoso.

Durante a pesquisa sobre o Candomblé em Pernambuco, iniciavam-se as fotos quando as pessoas estavam ficando mais ambientadas com presença do pesquisador, o que poderia levar algumas horas. O equipamento pode dificultar os primeiros contatos, mas depois do pesquisador ser aceito, as pessoas se acostumam e nem se importam mais. Esse comportamento não era tido como uma regra, algumas vezes foram feitas imagens logo na chegada ou no início, o que é importante colocar é que é necessário que ocorra uma integração com um grupo que passa pela adaptação das pessoas com o fotógrafo/pesquisador.

A sensibilidade do pesquisador ao negociar sua participação com o grupo escolhido vai ser peculiar toda vez que o Termo de Consentimento Livre e Esclarecido for solicitado. Ou seja, em alguns casos encontram-se pessoas analfabetas, situações em que o "outro" não tenha como assinar - como no caso Arco Verde, que um babalorixá não sabia escrever, mas concordava em autorizar a sua participação. Por saber que muitas pessoas não sabem escrever, ofereceu-se a opção de um termo de consentimento

\footnotetext{
${ }^{13}$ A forma que seria mais superficial de representação não deve ser desprezada, pois ela pode ser importante para análise dos dados coletados.

${ }^{14}$ Apud. Malinowski, B. Argonautas do Pacífico Ocidental. São Paulo: Abril Cultural, 1976. p.35.
} 
gravado em vídeo, ou mesmo gravado com um gravador antes ou ao invés de pedir que assinem.

É importante lembrar que se o Termo de Consentimento Livre e Esclarecido for pedido no final do trabalho e o entrevistado negá-lo, sua escolha deve ser respeitada e as informações oferecidas por ele não devem ser utilizadas, pois como consta no código deontológico do antropólogo, só participa quem quiser e consentir. Isso já aconteceu durante umas fotos realizadas com algumas pessoas nos terreiros. Após fotografar, o pesquisador foi pedir que as pessoas consentissem a participação, mas o pedido foi negado. Não concordaram, como também foi pedido para deletar as imagens, a vontade delas foi cumprida na hora e diante delas. Essa atitude serviu tanto como forma de respeito à alteridade, como uma postura ética que levou a aumentar o reconhecimento do respeito com o grupo.

Alguns antropólogos optam por ocultar sua identidade, nem que seja por um período mais curto até conseguirem entrar no grupo que desejam estabelecer uma relação. Essas formas de trabalhar não serão analisadas nesse trabalho, o que vamos colocar é que a opção escolhida é o contato direto com a apresentação do Termo de Consentimento Livre e Esclarecido e com a ajuda de um "amigo" que possa fazer a introdução do pesquisador dentro do grupo. Muitas vezes o "amigo" é pago pelo serviço e pode ser contratado como assistente ou guia.

\section{A etnografia}

O fotógrafo/pesquisador, quando pratica a etnografia, tem que entender o que é esta prática. É justamente essa compreensão que fará com que ele entenda o que é a análise antropológica como construção de conhecimento (Geertz, 1998). A fotografia entra nesse processo de prática etnográfica e não devemos entendê-la como uma questão puramente de metodologia. Ela é uma linguagem visual complexa, que quando bem usada, como coloca Milton Guran (2002: 98), pode potencializar e dar ênfase a aspectos que passam despercebidos pela visão.

Então, durante a prática das fotografias etnográficas nos terreiros de Recife, a coordenação da pesquisa orientou a produção de imagens que captassem os movimentos das danças, os gestos e os objetos, principalmente os que representavam os quatro elementos da natureza. Nesse processo empírico, foi percebido pelo pesquisador/fotógrafo que se defrontava com duas situações: com o passar do tempo 
fotografava para "contar" 15 , que eram imagens que ajudariam a transpor os problemas de pesquisa; ao passo que em um segundo momento percebia "quanto mais os antropólogos trabalham sobre a fala, sobre as narrativas, em busca dos significados, mais difícil se apresenta transformar estas falas e as categorias que elas se articulam em imagens" (Godolphim, 1995: 2).

Por esse motivo, quando o fotógrafo não for o antropólogo, ou vice-versa, e sim uma dupla, é importante que o primeiro saiba bem quais categorias antropológicas estão sendo utilizadas para que possa articula-las com as imagens. A sintonia dos profissionais envolvidos no campo vai facilitar que as fotos possam ser montadas em uma narrativa visual ${ }^{16}$, o que ajuda a percepção do espaço e tempo e aumenta as possibilidades interpretativas da cultura que esteja sendo estudada. Existem formas de trabalhar com narrativas visuais como no caso de Alves (2004: 112) que fazia as fotos, apresentava ao grupo de caranguejeiros e, "a partir da maneira como eles pensam a sua realidade, traçar o "fio condutor" da pesquisa". Ele continua se referindo a essa ideia como sendo um caminho já utilizado por outros autores, como Robert Flaherty, em 1922.

A opção de trabalhar com narrativas visuais foi utilizada na pesquisa aqui citada, e durante esse trabalho percebeu-se que em um certo momento chegávamos no "segredo". Em diferentes casas de Candomblé, as fotos podiam ser feitas até um determinado momento, ou então só poderia fotografar após um ritual. Fui percebendo que não existia uma regra geral, pelo contrário, em cada terreiro a conduta mudava, inclusive alguns como o de Arco Verde, mencionado anteriormente, tudo podia ser fotografado. Durante a etnografia, mesmo quando era autorizado as fotografias, o grupo se deparava com "segredo", que não é bem delimitado e muitas vezes o fotógrafo pode exceder as barreiras do permitido, o que pode causar um constrangimento.

\section{O segredo}

Quais os fatores místicos, políticos e sociais que influenciam e determinam os limites e como o fotógrafo/pesquisador pode tentar adquirir determinada imagem com

\footnotetext{
${ }^{15}$ Corresponde ao momento que o fotógrafo já conhece e, de certa forma, domina o seu objeto de estudo. Ver (Guran, 2002: 98).

${ }^{16}$ Entenderemos a narrativa visual comparado a um texto narrativo, como um recurso que o pesquisador tem para falar da realidade. "Trata-se de uma nova forma narrativa concebida na perspectiva de uma antropologia interpretativa tendo uma de suas características a de se oferecer como escrita [...]' (Achutti, 2004).
} 
consentimento, se esta for necessária como dado etnográfico na pesquisa. A reflexão ocorre muito mais para entender possíveis comportamentos do que para generalizar ou julgar as atitudes que compõe as normas dos terreiros.

Em Itabuna, no terreiro Ilê Axé Ijexá Orixá Olufan, foi proibido fotografar dentro do salão onde ocorrem as festas e cerimonias para os Orixás, o babalorixá da casa, também consultor da pesquisa, foi consultado sobre o por que de não poder ser fotografado. Ele respondeu energicamente que não pode, o Orixá patrono da casa não permite, desrespeitá-lo seria profanar um espaço sagrado. Ao retornar para Recife, durante um encontro com Cláudio, o "amigo" da pesquisa, perguntou-se sobre a possibilidade de fotografar uma matança, ele respondeu que dependia do tipo de serviço. Ao persistir a pergunta, ele disse que poderia consultar o Orixá, após o jogo de búzios a resposta foi que sim, e o jogo confirmou ${ }^{17}$ a liberação das fotos.

Fazendo uma retrospectiva histórica, podemos nos referir a 15 de novembro de 1951, quando na revista O Cruzeiro, com o título "As noivas dos deuses sanguinários", foi publicada uma série de 38 fotografias sobre a iniciação de três Iâos $^{18}$, feitas pelo repórter fotográfico José de Medeiros em um terreiro de Candomblé na Bahia. Essas fotos e a maioria dos acontecimentos que envolvem essas imagens são narrados por Fernando de Tacca em uma minuciosa investigação sobre o ocorrido (Tacca, 2009). José de Medeiros foi até Salvador tentar fazer fotos que, segundo ele, mostrassem o que é realmente o candomblé no Brasil. Ele percorreu vários terreiros tradicionais que negaram, mas no da Mãe Riso, no bairro da Plataforma, a autorização foi consentida, desde que eles pagassem (Tacca, 2009). Dois fatos nesse caso vão nos interessar: a autorização por parte do pai ou mãe de santo e, consequentemente, do Orixá.

Ao realizar a pesquisa sobre as imagens de José de Medeiros, Tacca (2009) pediu autorização para fotografar uma iniciação de Iaô que seria concedida por um Pai de santo, desde que eles negociassem: "Quando perguntei a Jorlando ${ }^{19}$ se eu poderia fotografar todo o processo de iniciação no seu terreiro, fui surpreendido com sua resposta positiva, e pareceu-me claro que tudo dependeria de um acordo financeiro, em relação aos custos de um ritual” (Tacca, 2009: 33).

No segundo momento, seria o fato de que, se o "segredo" fosse fotografado, existiria uma profanação do sagrado e vários acontecimentos ruins seriam sofridos pelos

\footnotetext{
${ }^{17}$ No caso de Claudio ele se comunica com os Orixás consultando o jogo de búzios, ele pertence à nação Nagô.

${ }^{18}$ Iâo é o termo usado para se referir a um iniciado na religião do candomblé.

${ }^{19}$ Jorlando de Obaluaê, Bairro do Uruguai, Salvador (BA).
} 
filhos de santo que aparecerem nas imagens e pelos pais ou mães de santo responsáveis pelo terreiro. Os fatos pesquisados cuidadosamente por Tacca (2009) nos levam a considerar que nesse caso, inclusive todos os envolvidos no culto que foi fotografado por José de Medeiros, não tiveram nenhum problema quanto a perseguições místicas ou sociais. Inclusive há o relato de Leleca ${ }^{20}$ falando sobre a irmã, a mãe Riso, que foi a responsável pela autorização das fotos para reportagem da revista Cruzeiro.

Riso dizia que não tinha medo sobre toda essa história, não tinha feito nada demais, que o santo não tem mais segredo... ela fez aquilo com autorização do santo, porque ela tinha santo mesmo... então o santo autorizou fotografar... ela fez com autorização do Orixá dela... depois que ela foi para o Rio, lá ela abriu casa, de muito prestigio...

(Leleca, apud. Tacca, 2009: 49)

Essas fotos foram consentidas, mas deixaram uma série de implicações que podem ser observadas, como coloca Tacca:

O formato de apresentação do material etnográfico nos meios de comunicação em massa e suas consequências com a invasão do olhar do leigo, voyeur e massificado, muitas vezes preconceituoso e induzido pela mídia em relação às cerimônias e rituais tradicionais de culturas locais não globalizadas, produzem significações descontextualizadas, muitas vezes pejorativas e elevadas ao campo do exótico e da humilhação."

(Tacca, 2009: 28)

As imagens chegaram a ser publicadas novamente pela equipe do Cruzeiro, em 1957. Dessa vez menos sensacionalistas, porque foram publicadas em um livro. Um fato que embute um segundo problema que seria uma falta total de comunicação com as pessoas registradas nas imagens, sem elas nem ao menos terem sido informadas (Tacca, 2009).

O fotógrafo José de Medeiros não conseguiu a autorização nos terreiros tradicionais que negaram o acesso e a permissão. Esse é um fato que mesmo decorridos mais de 60 anos após as foto da revista O Cruzeiro, os comportamentos se repetem. Durante a pesquisa do Núcleo do Imaginário, também tivemos os mesmos problemas. O acesso `as casas consideradas não tão tradicionais foi mais fácil. Esta relação de hierarquia no Candomblé com o mais "tradicional", que estaria ligado a uma ideia de “pureza”, vem sendo percebida por alguns pesquisadores como Beatriz Dantas ${ }^{21}$. Ela, em 1988, publicou um livro em que faz uma pesquisa que vai desde os estudos de Nina

\footnotetext{
${ }^{20}$ Angioleta Silva dos Santos, irmã de sangue de Riso.

${ }^{21}$ Dantas, B. Vovó nagó e papai branco: usos e abusos de da África no Brasil. Rio de Janeiro: Graal, 1988.
} 
Rodrigues, que já colocava a semelhança de traços culturais do Candomblé brasileiro como prova de "sobrevivência" (Rodrigues, 1935; 1977; Ramos, 1951; 1961), passando por Roger Bastide e outros autores, que contribuíram segundo Dantas (1988) para a noção de que:

Considerando os candomblés, sobretudo os candomblés mais "puros", como reduto de africanidade e de resistência, os autores que adotam essa postura metodológica implicitamente aceitam que, no Brasil, a presença de traços culturais originários da África, necessariamente indica resistência do negro.

(Dantas, 1988)

No decorrer do livro Dantas (1988) refere que a tendência desses autores, que são antropólogos, de considerar a religiosidade nagô como sendo a "pura", causa um processo de hierarquia que diminui as demais consideradas "misturadas". A autora fala da escrita etnográfica como fator de influência para construção de uma estratificação, mas essa deve ser associada a fotografia etnográfica também como coloca Lisa Castillo:

Ademais descobri que os usos êmicos da fotografia foram acompanhados por práticas envolvendo a escrita. Desta forma, percebi que para poder compreender adequadamente as percepções sobre a etnografia, tanto visual como textual, era interessante ampliar o campo de estudo mais ainda para analisar os usos êmicos da escrita e da fotografia.

(Castillo, 2005: 14)

Castillo (2005), ao encontrar fotografias antigas dentro de terreiros de Salvador, percebe que essas imagens eram retratos de pessoas ou personalidades que tinham algum parentesco africano, o que valorizava a ancestralidade africana, afirmando uma memória que prestigiava uma "pureza" nagô, como vimos com Dantas (1988), uma herança da antropologia.

Assim, a fotografia junto com a escrita etnográfica criou uma identidade associada a uma pureza considerada como tradicional, o que dá um prestígio a determinados Candomblés. Essa herança vai demostrar uma atitude que segundo Castillo (2005) é sintomática nos terreiros, enquanto os "tradicionais" não querem e evitam ao máximo que suas festas e comemorações sejam fotografados, os mais novos vão liberar as fotos, porque acreditam que a construção de acervos de imagem vai facilitar a construção de uma identidade que não existia por não ter uma ligação africana. Quando a imagem torna o terreiro visível na mídia, ocorre uma "valorização", como coloca Reginaldo Prandi (1991): 
Nos dias de hoje, neste jogo de afirmação, importantíssimos são a mídia, os movimentos artísticos e culturais e as instituições oficiais encarregadas de definir, selecionar e preservar aquilo que possa ser definido como "tradição" para a sociedade brasileira, ou seja, os órgãos de tombamento patrimonial.

(Reginaldo Prandi, 1991)

Lisa Castillo afirma que existem fatores que envolvem o controle do "segredo" nos terreiros "tradicionais", como " hierarquia interna formal, concorrência interna pelo poder, e o contexto social externo" (Castillo, 2005: 22). Então, a fotografia que hora serviu para legitimar uma identidade nos terreiros "tradicionais" sendo usada para mostrar através de retratos antigos laços com parentes africanos, agora deveria ser evitada para que a sobrevivência desses terreiros não fosse ameaçada por uma visibilidade característica da imagem etnográfica, assim a tradição deve continuar pela invisibilidade ${ }^{22}$.

Segundo as pesquisas realizadas por Castillo (2005) as fotos podem adquirir uma utilização de amuleto $^{23}$, ou mesmo de oferenda ${ }^{24}$ - para os integrantes do candomblé a imagem passa a ser simbolicamente a pessoa, então ela pode ser usada em magias. A fotografia, além de representar a pessoa, se torna uma parte da pessoa, o que pode ser um risco para os integrantes do candomblé que podem se tornar alvos de feitiços. Um exemplo dessa prática foi comentado por Claudio quando disse que os "mestiços" 25 costuravam uma foto do desafeto na boca do sapo para que o animal morresse sofrendo com fome e consequentemente a pessoa que estava representada pela foto também.

A proibição das fotografias e da escrita etnográfica dentro de um terreiro pode estar relacionada a aspectos como a transmissão de conhecimentos. Existe uma série de ensinamentos que vão sendo transmitidos pelos mais velhos para aqueles que permanecem e que são iniciados na religião, criando laços nos terreiros e que com o passar do tempo vão recebendo a confiança para saber dos ensinamentos secretos. Como coloca Reginaldo Prandi (1991):

Todo terreiro de candomblé estabelece com a sociedade um conjunto de relações econômicas e sociais. No interior do próprio terreiro, o pai-de-santo ou a mãe-desanto atua como chefe espiritual, mas também como micro-empresário que controla

\footnotetext{
${ }^{22}$ A invisibilidade como fator de proteção que envolve o cotidiano de uma casa de Candomblé pode resguardar aspectos que para os integrantes deva ficar anônimos como o "segredo", os "feitiços" e a exposição pejorativa em mídias populares como vimos no caso da revista Cruzeiro.

23 Amuletos são chamados de patuá.

${ }^{24}$ Que geralmente são chamados de ebó.

${ }^{25}$ Integrantes de terreiros que não são adeptos apenas do candomblé, eles cultuam o catiço.
} 
o fluxo de gastos e ganhos, acumulando e capitalizando nas infra-estruturas dos terreiros os recursos sobrastes. Então existe uma questão que envolve o segredo que é qual o destino dessa informação e como ela vai ser usada.

(Prandi, 1991: 198)

No geral o convívio com as pessoas do Candomblé pode gerar uma relação que vai envolver um compromisso e dedicação tanto espiritual como material. O envolvimento como pesquisador passa pela participação do mesmo, ele vai ter que adquirir a confiança que muitas vezes pode levar anos. Até chegar na fotografia de rituais secretos, o pesquisador/fotógrafo pode ter até que passar por rituais de limpeza, manter resguardo de sexo e bebidas alcoólicas entre outras restrições que podem variar de acordo com a nação ${ }^{26}$.

Conseguir o consentimento para fotografar o "segredo" nos terreiros "tradicionais" pode ser só após uma iniciação religiosa, o que criaria um vínculo do pesquisador. Nos terreiros mais novos, o fotógrafo/pesquisador pode conseguir bem mais fácil fazer essas fotos, inclusive uma publicação das mesmas pode demonstrar como os rituais estão sendo realizados conforme as tradições africanas. Essa relação pode gerar inclusive análises antropológicas que indiquem "pureza" e, atrelados à imagem, que é uma prova visual de uma realidade, eles podem ser considerados "tradicionais", o que aumentaria o status do terreiro.

De acordo com Simmel (2007), a relação entre seres humanos envolve o conhecimento de alguma coisa da vida do outro. Assim também o é na relação entre pesquisador/fotógrafo e o "outro", onde sempre ocorrerão interditos, que envolvem segredos. O pesquisador/fotógrafo deve se colocar no lugar do pesquisado e questionar se tudo sobre a sua vida pode ser desvelado, se ele mesmo possui seus segredos ou elementos de sua vida sobre os quais prefere não falar, ou opta por comentar apenas com poucas pessoas com quem mantém relações diferenciadas. Ou, para além disso, haveria elementos sobre os quais o "pesquisado" fala apenas com o pesquisador, que o incita a refletir sobre coisas antes impensadas? Neste sentido, o que importa, então, não é o conteúdo da imagem ou da revelação, mas a permissão para tirá-la (Castillo, 2008).

\section{Considerações finais}

A Revista $O$ Cruzeiro de 15 de novembro de 1951 sem dúvida é um marco na produção e divulgação de imagens religiosas no Brasil. Mas talvez tais imagens não

\footnotetext{
${ }^{26}$ Nação é como se designa as diferentes etnias que cultivam determinado Orixá.
} 
devessem ter sido expostas na grande mídia, porque se tratavam de imagens de um ritual com sacrifício de animais e sangue. Uma exposição de fotos dessa forma para um grande público pode acabar provocando um efeito de preconceito contra o candomblé, que como no caso da publicação citada, repercute até hoje. Mas essa veiculação das fotos na revista de maneira equivocada pode ser pertinente para lançar uma discussão sobre a responsabilidade do fotógrafo/pesquisador, que deve refletir sobre a ideia de que imagens estão carregadas de ideologias (Kossoy, 2000), principalmente quando impressas em algum tipo de mídia.

A responsabilidade do fotógrafo em relação à identidade das pessoas é sempre maior, principalmente quando situado dentro de uma pesquisa que estuda uma religião que tem em sua prática rituais secretos. A autorização pode ser consentida, mas o envolvido ou o grupo social pesquisado pode não querer se identificar, o que pode exigir do fotógrafo habilidade para fazer fotos que não identifiquem os seus personagem.

Durante a pesquisa nos terreiros de Candomblé de Pernambuco, por várias vezes foi discutido o problema de que nas festas sempre vinham uma quantidade considerada de visitantes. Depois que a celebração começava, não podia mais parar, e a consequência era que o pai de santo não tinha como anunciar a presença do pesquisador/fotógrafo e o termo de autorização de imagem ficava mais difícil de ser assinado pelos visitantes. Foram inúmeras as festas que frequentadas durante a pesquisa, e com o passar do tempo percebemos que só tínhamos no caso a autorização do dono do terreiro. A solução encontrada de preservar a identidade daquelas pessoas que estavam nas festas e não assinaram o termo foi cortar o rosto no enquadramento das fotos. As fotografias então adaptaram-se a um formato que não mostrava o rosto, o que não descaracterizava o acontecimento, pois bastava mostrar as fotos para algumas das pessoas que participavam da festa e elas logo identificavam onde tinha ocorrido ou até mesmo quem era.

Com o passar do tempo, aderiu-se a ideia de fotografar preservando identidade da pessoas, principalmente em locais de conflito ou que pudessem envolver alguma implicação relacionada a divulgação das imagens. Essa pode ser uma forma de resguardar o "outro" e o fotógrafo/pesquisador - Não identificar as pessoas pode ser uma tarefa bem mais difícil de ser executada e ao mesmo tempo uma forma de cuidado com o "outro".

Preservar a identidade de quem não foi devidamente informado e esclarecido 
sobre as intenções de uma pesquisa é muito importante, pois se pensarmos que a fotografia tem uma credibilidade muito grande, quando as pessoas veem uma foto, em geral, elas logo acreditam no discurso que está sendo desenvolvido. Portanto, podemos supor que uma pessoa não goste de ver sua imagem publicada em um artigo, tese ou qualquer outra mídia usada pela academia em que exista uma análise crítica sem ter consentido.

$\mathrm{Na}$ antropologia, a foto era uma forma de mostrar o "estar lá", assim, o pesquisador comprovava que esteve no campo, o que servia como estratégia de convencimento para construção de etnografias (Geertz, 1998). Mesmo que as imagens componham um trabalho etnográfico no qual a antropologia poderia inserir a fotografia em um espaço e tempo de legitimidade das ciências sociais, estas carregam uma herança positivista de que são cópiais do real ${ }^{27}$ - o que vai dar essa credibilidade do "esteve lá" (Geertz, 1998), é toda uma herança que a fotografia carrega desde o seu surgimento ${ }^{28}$, em que "os modernos veem na mecanização o meio de incrementar a eficácia da representação" (Rouillé, 2005: 32).

Essa ideia de que o grande público acredita na imagem como uma copia do real, pode parecer ultrapassada principalmente com o surgimento e a popularização das imagens digitais e dos programas de computadores que facilmente manipulam uma imagem. Ao passo que uma imagem pode servir para fazer um ebó em um terreiro de Candomblé ou mesmo servir como prova de que um pai de santo realiza uma cerimônia de acordo com a tradição africana.

Então a fotografia assim como a escrita etnográfica sempre estará sujeita a críticas, mas o que vai garantir a sua eficácia simbólica ${ }^{29}$ nos terreiros é a sociedade alimentar uma crença positivista na imagem como espelho do real - um mito que não pertence a fotografia, não faz parte da sua constituição ou das suas propriedades técnicas, mas a sociedade, assim como os integrantes do terreiro, atribuem a ela como sendo uma característica ou uma propriedade - de copiar e representar o real.

\footnotetext{
${ }^{27}$ Ver Barthes, R. A câmara Clara. Lisboa: Edições 70, 2009.

28 "O caráter de prova irrefutável do que realmente aconteceu, atribuído à imagem fotográfica pelo pensamento da época, transformou-a num duplo da realidade, num espelho, cuja magia estava em perenizar a imagem que refletia. Para muitos artistas e intelectuais, dentre eles o poeta francês Baudelaire, a fotografia libertou a arte da necessidade de ser uma cópia fiel do real, garantindo para ela um novo espaço de criatividade. Baudelaire expõe, nesta passagem de seu artigo 'O público moderno e a fotografia', qual era, para ele, o verdadeiro lugar da fotografia dentre as formas de expressão visual de meados do século XIX."(Mauad, 1996: 1).

${ }^{29}$ Lévi-Strauss, C. "A eficácia simbólica”. In: Antropologia Estrutural. Rio de Janeiro: Tempo Brasileiro, 1997.
} 
No último dia 30 de junho aconteceu a festa de Iemanjá no Ilé Iyeminjá Ògunté, e lá estavam cinco fotógrafos para registrar a festa. Na entrada da casa, era necessário identificar-se, para ser encaminhado a pessoa responsável pelo credenciamento para fazer as fotos e que só era liberado com um crachá. Então, mesmo no panorama da massificação e da popularização das imagens, os terreiros encontraram uma forma de controlar quem fotografa e por que está fotografando. No decorrer da festa, a filha da mãe de santo falou o seguinte: "só bata foto quem estiver com crachá, quem bater fotos com celulares ou câmeras e postar nos facebook ${ }^{30}$ da vida, aguente o processo".

O que pode-se perceber é que os integrantes dos terreiros compreendem a concepção política $^{31}$ no ato de fotografar. A percepção dessa compressão surgiu com um controle das imagens, regulados pela confiança, pois todos os fotógrafos eram conhecidos ou participantes da casa. A festa e as representações que aconteciam durante o evento estavam sob o código de confiança estabelecido entre o terreiro e os fotógrafos participantes, criando assim um padrão ético que regula possíveis veiculações das imagens. E mais do que isso, pois essa permissão pressupõe um retorno das fotos para os integrantes do terreiro.

A experiência estabelecida com o Ilé Iyeminjá Ògunté, demostra que mais do que nunca o código deontológico está se firmando como uma forma de se estabelecer relações de qualidade e que possam ser equivalentes entre os pesquisadores e os grupos sociais. A conduta ética deve exceder os limites do trabalho e ser incorporado no conjunto de atitudes diárias. É bom ter a permissão para fotografar e pesquisar, pois isso vai dar a base empírica para o trabalho, mas tem que ser bom para "outro" também, e uma forma desse retorno acontecer é a entrega das fotos impressas ou mesmo em um DVD.

A ética prossegue na reflexão proposta nesse trabalho no sentido de que é possível fotografar o "segredo" em terreiros, desde que exista uma relação livre e esclarecida. A fotografia, se permitida, não lança pragas ou castigos aos integrantes, como visto em alguns casos em que fotos foram realizadas e tudo ocorreu bem, sem castigo divino. O que é importante é que liberado ou não, o fotógrafo/pesquisador tem que saber em que suas atitudes influenciam ou demonstram as singularidades do grupo estudado.

Um terreiro dito como novo, sem raiz africana, pode aceitar uma pesquisa

\footnotetext{
${ }^{30} \mathrm{http}: / / \mathrm{www} \cdot$ facebook.com/

${ }^{31}$ Entenderemos a politica como sendo uma dimensão de qualquer ação humana, ver (Goldman, 2006).
} 
etnográfica com a intenção de exibir seus procedimentos e ser avaliado por um antropólogo. Isso dará uma visibilidade que poderá legitimar e integrar o terreiro em políticas públicas. Também estão envolvidas as relações de poder dentro do terreiro e o status social adquirido por um estudo antropológico. A liberação para fotografar o "segredo" não é o início nem o fim, mas uma etapa da pesquisa a ser analisada como qualquer outra.

As várias condições que envolvem a liberação de fotografar ou não, a almejada autorização, passa pela postura do fotógrafo/pesquisador que deve, pacientemente, tentar entender os motivos que podem tencionar o comportamento do "outro". Por mais que se descubra o motivo da proibição, só participa quem quiser, só se publica foto com consentimento. $\mathrm{O}$ direito inclusive esclarece os dois aspectos que envolvem o uso de imagem, que seria o direito do fotógrafo que fez a imagem e das pessoas que aparecem. As imagens que identificam as pessoas tem direitos conexos entre fotógrafo/pesquisador e o "outro".

Não existem leis que determinem a punição pela atitude dos pais de santo que liberam a divulgação do "segredo". Não creio em uma regra universal para terreiros que ao liberar imagem profanam o sagrado - até mesmo porque, como vimos, o sagrado também consente. Mas existem leis que punem os fotógrafos/pesquisadores que não respeitam o direito de imagem do "outro". Como colocou Achutti (2004) o pesquisador deve quem sabe até preservar os "sonhos" do "outro".

$\mathrm{O}$ fotógrafo independente de ser pesquisador sempre deve estar atento e preparado para captar imagens. O que vai determinar se suas fotos vão poder ser publicadas ou não é a autorização. A foto pode ser batida e se não consentida apagada na mesma hora na frente da pessoa que não autorizou. Isso é algo que acontece na etnografia não como um artificio para burlar uma postura ética, mas porque o fotógrafo/pesquisador está misturado, homogeneizado com a vida e com o cotidiano do grupo social. Um caso que isso pode acontecer é se aparecer uma pessoa nova e esta for realizar algo importante junto com o grupo social pesquisado, o fotógrafo não deve parar o acontecimento para pedir a autorização, essa deve só vir após o acontecimento. Como coloca Achutti (2004), o fotógrafo não deve estar próximo demais para não interferir nos acontecimentos, ao mesmo tempo que não deve estar longe o suficiente para que não perca nenhum fato singular.

A tecnologia chegou para ajudar e facilitar o processo de etnografia, antes não podíamos mostrar uma foto na hora que esta era batida. Um fotógrafo poderia passar 
meses com um grupo e não mostrar uma única foto. Hoje as fotos podem ser batidas, as pessoas podem ver na hora e os comentários que fazem sobre as suas fotos podem ser inseridos como dados de pesquisa. A autorização para fotografar o segredo pode passar por uma negociação que inclua a chance do "outro" ver as fotos e analisar se tem algo que seja impróprio para ser revelado. Assim, a participação por mais curta que seja de um pesquisador pode ganhar uma integração importante entre o observador e o observado.

Acredito que existem inúmeras possibilidades que facilitam uma liberação de fotografar, mas a experiência com a fotografia de pesquisa me leva a crer que o que importa é respeitar o próximo, manter boas relações, criar "amigos" e produzir informações que possam contribuir para as pessoas pesquisadas.

\section{Referências}

ACHUTTI, L.E.R. Fotoetnografia da biblioteca jardim. Porto Alegre: Ed. UFRGS/Tomo editorial, 2004.

ALVES, A. Os argonautas do mangue: precedido de Balinese Character (RE) Visitado por Etienne Samain. São Paulo: Ed. UNICAMP, 2004.

ANGROSINO, M. Etnografia e observação participante. Porto Alegre: Artmed, 2009.

BARTHES, R. A Câmara Clara. Lisboa: Edições 70, 2009.

BOAS, F. Handbook of American Indian Languages - Part 1. Washington: Government Printing Office, 1911. p.59-73.

BOURDIEU, P; BOURDIEU, Marie-Claire. "O camponês e a fotografia". In: Revista de Sociologia e Política, n.26. Curitiba: UFPR, 2006. p. 31-39.

BRAGA, J. Na gamela do feitiço, repressão e resistência nos candomblé da Bahia. Salvador: EDUFBA, 1995.

CASTILLO, L. E. Entre a oralidade e a escrita: etnografia nos candomblés da Bahia. Salvador: EDUFBA, 2009.

DANTAS, B. Vovó nagó e papai branco: usos e abusos da África no Brasil. Rio de Janeiro: Graal, 1988.

DANTAS, E. "A Construção do olhar do fotógrafo em pesquisas de ciências sociais". In: Revista Pense Direito, v.4, n.6. Olinda: AESO, 2011.

GEERTZ, C. A interpretação das culturas. Rio de Janeiro: LTC, 1998.

GODOLPHIM. N. "A fotografia como recurso narrativo: problemas sobre a apropriação de imagem enquanto mensagem antropológica". In: Horizontes Antropológicos, ano 1, n.2. Porto Alegre: UFRGS, 1995. p. 161-185.

GOLDMAN, M. Como Funciona a Democracia: uma teoria etnográfica da política. Rio de Janeiro: 7 Letras, 2006.

GURAN. M. Linguagem fotográfica e informação. Rio de Janeiro: Editora Gama Filho, 2002.

KOSSOY, B. Realidades e ficções na trama fotográfica. São Paulo: Ateliê Editorial, 2000. 
LÉVI-STRAUSS, C. "A eficácia simbólica". In: Antropologia Estrutural. Rio de Janeiro: Tempo Brasileiro, 1997.

MALINOWSKI, B. "Introdução". In: Os argonautas do Pacífico Ocidental. Coleção Os Pensadores. São Paulo: Ed. Abril, 1978. p. 17-34.

MAUAD, A. "Através da imagem: fotografia e história interfaces". In: Tempo, v.1, n.2. Rio de Janeiro: UFF, 1996. p. 73-98.

PEIRANO, Mariza G. S. “A legitimidade do folclore”. In: Seminário Folclore e Cultura Popular: as muitas faces de um debate. Rio de Janeiro: Funarte, 1992. p. 85-8.

PRANDI, R. Os candomblés de São Paulo: a velha magia na metrópole nova. São Paulo: Ed. HUCITEC, 1991.

RAMOS, A. As culturas negras no novo mundo. São Paulo: Companhia Editora Nacional, 1979 [1937].

RODRIGUES, N. Os Africanos no Brasil. Brasília: Editora Universidade de Brasília, 1982 [1906, 1932].

ROUILLÉ, A. A fotografia: entre o documento e a arte contemporânea. São Paulo: Ed. SENAC, 2009.

SIMMEL, G. "O segredo”. In: Política e Trabalho: Revista de Ciências Sociais, n.15. Tradução Simone Maldonado. João Pessoa: PPGA/UFPB, 1999.

TACCA, F. "Candomblé - Imagens do Sagrado". In: Campos - Revista de Antropologia Social. Curitiba: UFPR, 2009.

Recebido em: 31/10/2012

Aprovado em: 21/12/2012 